\title{
MAYO DEL 68 Y LOS CATÓLICOS CATALANES
}

\author{
POR \\ Francisco Martínez Hoyos
}

\section{RESUMEN}

En 1968, la Iglesia catalana vivía en plena crisis postconciliar. Los sectores más progresistas se sentían decepcionados porque no se habían producido los cambios que esperaban tras el Vaticano II. Los acontecimientos parisinos inciden sobre este contexto eclesial, marcado por la división y el influjo del marxismo. El artículo se centra en las reacciones de Alfonso Carlos Comín, El Ciervo y el clero representado por la revista Correspondència.

Palabras ClaVes: Mayo del 68, crisis postconciliar, Alfonso Carlos Comín, El Ciervo, clero progresista.

\section{MAY 68 AND THE CATHOLIC CATALANS}

\begin{abstract}
In 1968, the catalonian Church lived in a full post-council crisis. The most progressive sections felt themselves disappointed because the expected changes after the Second Vatican Council did not achieve. The parisian events affect this ecclesiastic context, which is accentuated by division and the marxism influence. This article is focused on the responses of Alfonso Carlos Comín, «El Ciervo» magazine and the clergy represented by the «Correspondència» review.
\end{abstract}

KEY WORDS: 68 may, post-council crisis, Alfonso Carlos Comín, «El Ciervo», progressive clergy

$\begin{array}{ll}\text { Recibido/Received } & 12-05-2011 \\ \text { Aceptado/Accepted } & 06-02-2012\end{array}$

En uno de sus libros, el fallecido Joan Carrera, obispo auxiliar de Barcelona, constataba que, sin que se supiera muy bien cómo, una Iglesia, la catalana, que 
acaba de vivir su mayor momento de gloria, con el aire fresco del Vaticano II, se derrumba al poco tiempo. ¿Qué había ocurrido? ¿Por qué tantos sacerdotes y seglares dejaban sus filas? Los católicos, que en los duros tiempos preconciliares, habían permanecido en la Iglesia con una fidelidad ejemplar, ahora, en plena apertura, se marchaban en desbandada. Planteado así el problema, podríamos decir, desde la perspectiva de la ciencia política y la sociología, que Tocqueville acertó. El mayor peligro para un sistema autoritario se da justo en el momento en que empieza a cambiar:

«La experiencia enseña que el momento más peligroso para un mal gobierno suele ser aquel en que empieza a reformarse. (...). El mal que se sufría con paciencia, como algo inevitable, se antoja insoportable en cuanto se concibe la idea de sustraerse de él. Los abusos que se van eliminando parecen descubrir mejor los que quedan y hacen el sentimiento más insufrible; el mal ha disminuido, es cierto, pero la sensibilidad está más viva». ${ }^{1}$

Fue esto, exactamente, lo que sucedió con la Iglesia. El Concilio había despertado, en los sectores más renovadores, una profunda esperanza. Basta con fijarse en las expresiones que el propio Carrera utiliza, al evocar aquellos momentos: «El moment de creure que l'esperança i fins i tot les il.lusions esdevenien realitat», «aquell sabor de matinada fresca era de debó i no l'oblidarem mai més». Son, como podemos comprobar, expresiones fuertes. Al igual que la comparación que hace entre los sueños de cambio en la Iglesia y La estaca, la canción de Lluis Llach, con su popular estribillo: «Segur que tomba, tomba, tomba... i ens podrem alliberar». ${ }^{2}$

Juan XXIII venía a dar la razón a los católicos más renovadores, los que dentro de España habían planteado, ya desde los años cuarenta con la JOC, la apertura al mundo obrero, y a principios de los cincuenta la denominada autocrítica. Bajo la influencia del cristianismo francés (Maritain, Mounier...) se empieza a construir una religiosidad más comprometida con los problemas del mundo. En 1951 nace El Ciervo. Algunos años después, un núcleo de católicos se incorpora a un nuevo partido de izquierdas, el FOC (Frente de Obrero de Cataluña). Mientras tanto, fe y catalanismo van unidas en el CC (Cristo y Cataluña), donde encontramos a Jordi Pujol, o en Montserrat, de la mano del carismático abad Escarré. $^{3}$

\footnotetext{
${ }^{1}$ El Antiguo Régimen y la Revolución. Tomado de www.nodulo.org

${ }^{2}$ Carrera, J. 1994. Del postconcili al postprogressisme: Barcelona: Mediterrània.

${ }^{3}$ Para una síntesis general, Martínez Hoyos, F. 2007. «Cristianos contra Franco en Cataluña (19391975)». Historia del Presente 10: 61-80. Figuerola, J i Juncosa, I. 2008. L'Església catalana durant el franquisme (1939-1975), vol III: Barcelona: Claret. Véase asimismo L'Església rebel, reciente documental de Oriol Porta.
} 
Los grupos cristianos con mayor conciencia social intentan construir una nueva Iglesia, más pobre, más cercana al pueblo. Consideran que su lucha tiene que darse en dos frentes simultáneos, por un lado el intraeclesial (ejercer de instancia profética que despierte las conciencias de los fieles), por otro el político (construir el Reino de Dios en la Tierra).

La decepción, por desgracia, llegó pronto. Las viejas estructuras no se desmoronaban tan fácilmente. En 1966, una manifestación de sacerdotes, en protesta por las torturas a un estudiante comunista, es disuelta violentamente. Ese mismo año, la campaña «Volem Bisbes Catalans» expresará el rechazo a la imposición de un prelado foráneo, un «bisbe d'ocupació», Marcelo González. Su línea conservadora no facilitará las cosas en los años siguientes, pero cabe preguntarse si el recibimiento extremadamente hostil que le tributaron no contribuyó, en parte, a su incomprensión hacia las realidades más progresistas. Sea como fuere, no hay duda de que, durante unos años, la archidiócesis sufrió una fuerte conflictividad interna, presidida por un prelado convencido de que los católicos necesitaban «más fe y menos afanes reivindicativos». ${ }^{4}$

Así las cosas, los progresistas tienen la sensación de que el aliento conciliar se queda a medio camino, ante los límites infranqueables que marca la jerarquía. La publicación en 1968 de la encíclica Humanae Vitae, acerca del control de natalidad, reforzara esta impresión. Ese año, a juicio de Joan Casañas, marca el punto de inflexión entre la euforia conciliar y el desencanto. Poco a poco, son cada vez más los que tienen la impresión de que la Iglesia, más que avanzar, retrocede hacia el viejo autoritarismo de Pío XII.

La crisis del catolicismo catalán no es, evidentemente, un fenómeno aislado. Se enmarca en otra más amplia, tanto social como religiosa, de ámbito europeo. Son los años del postconcilio, una etapa que podemos convenir en prolongar hasta la muerte de Pablo VI, en 1978, en la que parecemos asistir a una especie de reacción thermidoriana para evitar que el aggiornamento del Vaticano II llegue demasiado lejos. Significativamente, algunas de las grandes figuras del Concilio, como Daniélou o Congar, toman distancia frente a las corrientes más avanzadas. Unos creen que el Vaticano II significa un punto de llegada, otros lo entienden como un punto de partida. Se enfrentan entonces distintas maneras de vivir la fe, cada una con sus propias premisas filosóficas y políticas. La autoridad jerárquica, mientras tanto, sufre un profundo deterioro, hasta el punto de que algunos temen que la unidad eclesial sucumba ante las «tendencias centrífugas». En Cataluña, más concretamente, abundan las fricciones entre el

\footnotetext{
${ }^{4}$ Sobre la campaña «Volem Bisbes Catalans», una visión nacionalista en Polo, X. 2005 «Todos los catalanes son una mierda»: 223-237 Bacelona: Proa.
} 
arzobispo y los sacerdotes, de forma que el prelado ya no puede dar por sentada la antigua obediencia de su clero.

No es extraño, pues, que Benedicto XVI, al rememorar aquella etapa, evoque un clima de notable confusión e inquietud. ${ }^{5}$

Tantas ilusiones rotas se deben, a nuestro juicio, a un profundo malentendido, la interpretación del Concilio en términos rupturistas, como si se tratara de una revolución en la historia del catolicismo. En realidad, las resoluciones del Vaticano II obedecieron a un espíritu de consenso, por lo que el ala más radical cedió en cuestiones decisivas. Cierto, por ejemplo, que la Iglesia pasaba a concebirse a sí misma como pueblo de Dios, en contraposición a la idea verticalista del pasado, pero también salía reforzada la autoridad suprema del papa. El pontífice continuaba disfrutando de una potestad suprema, por más que se afirmara que ésta pertenecía también al colegio de los obispos. De hecho, se especificó que los prelados no podían ejercer su autoridad «sin la cabeza». Por otra parte, aunque no se puede dudar del nuevo espíritu de diálogo con el mundo, si se debe matizar que este diálogo se efectuó desde posiciones paternalistas. Así lo reconocía el prestigioso historiador y teólogo Evangelista Vilanova. ${ }^{6}$

Por tanto, la crisis postconciliar no se debería interpretar en términos de una lucha entre partidarios del concilio y sus detractores, ya que, salvo una minoría de fanáticos, todos están de acuerdo en la importancia de lo acordado en Roma. Las diferencias se producen a la hora de interpretar el alcance de la renovación. Desde este punto de vista, Juan Pablo II y Benedicto XVI no serían los enterradores del Concilio, como quiere cierta historiografía progresista, sino los promotores de una determinada manera de entender su legado.

Las turbulencias eclesiales también se explican por las nuevas coordenadas en las que ha de ejercerse la militancia religiosa, las de un mundo cada vez más secularizado que la Iglesia ya no puede ni pretende controlar. Los católicos, a diferencia de lo que sucedía en el pasado, ya no viven en un mundo impregnado por los valores de su fe. Al contrario. Según el teólogo Rovira Belloso, la antigua cultura de cristiandad deja paso a una sociedad básicamente pagana.

«Hoy, la fe de las personas ya no tiene un arropamiento constituido por una cobertura «teísta» y por una práctica de «costumbres cristianas». Para poner uno de los ejemplos más populares, cabe decir que hoy día, cuando se presentan según qué dificultades o escollos en el matrimonio, se apela resueltamente a la separación, allí donde en el pasado había como un instinto «sagrado» de

\footnotetext{
${ }^{5}$ Graziano, M. 2012. El siglo católico: Barcelona, RBA.

${ }^{6}$ Carmona Fernández, Francisco J (Coord.). 2010. Historia del Cristianismo IV. El mundo contemporáneo: 415 Madrid: Trotta.
}

Hispania Sacra, LXV

131, enero-junio 2013, 425-445, ISSN: 0018-215-X, doi: 10.3989/hs.2013.013 
mantener la institución matrimonial. Ello pide, en los antiguos países de tradición cristiana, una fe sólida y madura, aunque siempre será comparativamente pequeña, como un grano de mostaza. Porque la cultura ambiente no es tan sólo «pluralista», sino que se parece mucho a la cultura pagana de los primeros siglos del cristianismo».?

En los países desarrollados, los cambios culturales derivados del crecimiento de económico se traducen en una transformación del sistema de valores, de forma que apenas queda terreno abonado para compromisos épicos. Tampoco para las ideologías fuertes, ya que lo que ahora domina es el denominado «pensamiento débil», ajeno a las certezas de los grandes relatos. La gente no está para aventuras colectivas, sí para disfrutar individualmente de la prosperidad. En España, las opciones revolucionarias, como el anarquismo, tan influyente en los años treinta, se vuelven casi por completo irrelevantes.

La revuelta parisina de mayo de 1968 vendrá a sacudir este panorama de aparente conformismo, marcado por la eclosión de la sociedad de consumo. En general, la historiografía no ha tendido a destacar el papel de los cristianos. París, sin embargo, fue el escenario de diversas manifestaciones de una fe en armonía con el progresismo más radical. El 25 de marzo de 1968, ocho grupos, tanto católicos como protestantes, participaban en el coloquio Cristianismo y Revolución. En su comunicado final dejaban la puerta abierta a la lucha armada. El 21 de mayo, Témoignage chrétien hace un llamamiento a los cristianos invitándoles a unirse a la contestación protagonizada por obreros y estudiantes. Según los firmantes, cuatro sacerdotes católicos, cuatro pastores protestantes y seis laicos (el filósofo Paul Ricoeur entre ellos), «la presencia de los cristianos en la revolución supone y requiere la presencia de la revolución en la Iglesia». Por primera vez desde el inicio de la movilización estudiantil, aparece públicamente este tema. ${ }^{8}$

En la misma onda se sitúa el graffiti «Le Christ seul révolutionnaire», captado por el objetivo de Cartier-Bresson, uno más de los que aparecen en las calles de París. En la ACO (Acción Católica Obrera), el combate obrero alcanzará prioridad sobre la evangelización, todo desde una perspectiva teológica en la que la lucha obrera se entiende como espacio de la manifestación de Dios ${ }^{9}$. Claro que, junto a los creyentes contestatarios que sueñan con cambiar el mundo en nombre de la fe, también encontramos el típico anticlericalismo de la izquierda.

\footnotetext{
${ }^{7}$ Rovira Belloso, J. M. 2008. Dios: Padre, Hijo y Espíritu Santo: 25 Salamanca: Secretariado Trinitario.

${ }^{8}$ Pelletier, D. 2002. La crise catholique : 33-29 París: Payot.

${ }^{9}$ Souletie, J. L.; Béarez, M. 2005. «La pertinence des mouvements d'Action catholique dans la mission de l'Église aujourd'hui». Repères ACO 72: 16.
} 
«Le cristianisme: l'ennemi ${ }^{\circ} 1 »$, reza otro de los eslóganes que proliferan en la capital del Sena». ${ }^{10}$

En contraste con el monolitismo eclesial de tiempos pasados, se multiplican las actuaciones que provocan sorpresa o escándalo, según los gustos. Así, el 2 de junio de 1968, los jóvenes de un grupo denominado CARE (Comité de Acción para la Revolución en la Iglesia), pertenecientes a la parroquia de Saint-Séverin (París), deciden que no van a celebrar la misa según lo acostumbrado. En su lugar organizan un forum para debatir los problemas de la comunidad eclesial. Hechos de este tipo se repetirán a menudo, como la reunión que tiene lugar en un teatro bajo el título «Del «Che» Guevara a Jesucristo».

El resplandor de la antorcha francesa deslumbra, desde luego, pero nos preguntamos si no estaremos pecando de eurocentrismo cuando contemplamos 1968 sólo desde el Sena. Porque, en América, ese es el año de la importantísima Conferencia Episcopal de Medellín, en la que el episcopado latinoamericano se pronuncia críticamente sobre el subdesarrollo de su continente. Este será el punto de partida de la teología de la liberación, interpretada por el historiador José Andrés Gallego como "aportación del 68». ${ }^{11}$ De sus fuentes beberá, poco más tarde, el movimiento de Cristianos por el Socialismo.

Se ha destacado, con razón, la influencia de los teólogos europeos sobre los teólogos de la liberación, por más que éstos acusen a los primeros de ignorar la problemática del Tercer Mundo. De hecho, muchas de sus grandes figuras se han formado en centros del viejo continente. Gustavo Gutiérrez estudió en la Universidad Católica de Lovaina y en Lyon. Y Karl Rahner dirigió la tesis de Leonardo Boff. Menos conocido, en cambio, es el influjo en sentido contrario, de América sobre Europa. Sin embargo, detectamos un creciente interés por las problemática latinoamericana en revistas progresistas como Études, una publicación de la compañía de Jesús, que dedica 21 artículos a estos temas entre 1960 y 1973 , cuando en el periodo anterior no había publicado ninguno. ${ }^{12}$

En España, mientras tanto, se da un fenómeno similar. Resulta significativo que El Ciervo, abanderada de un catolicismo abierto, dedique un número especial a Camilo Torres, el sacerdote colombiano que había muerto combatiendo con la guerrilla. Su fecha de aparición, mayo de 1968, resulta igualmente expresiva. Se trataba seguramente, de acuerdo con la revista, del primer monográfico sobre el tema publicado en Europa.

\footnotetext{
${ }^{10}$ Barrau, G. 1998. Le mai 68 des catholiques : 7 París : Éditions de l’Atelier.

${ }^{11}$ J. A. Gallego en AA. VV. 2008. Historia del mundo contemporáneo de la revolución a la globalización: 841-905 Valencia: Tirant lo Blanch.

${ }^{12}$ Compagnon, O. 2008. "Le 68 des catholiques latinoaméricains dans une perspective transatlantique". Materiales de seminarios, dentro de nuevomundo.revues.org/47243
} 
Para El Ciervo, Torres planteó problemas cruciales no sólo para el catolicismo latinoamericano sino para la Iglesia en su conjunto. Juan Gomis destacaba como aquel atípico sacerdote había aplicado, en el campo de la política, el mandamiento del amor al prójimo. Por otra parte, su actuación suscitaba una reflexión sobre si la lucha armada constituía el camino adecuado para cambiar la sociedad. Gomis, de acendradas convicciones pacifistas, señalaba cómo esta vía aparecía muy poco clara para los creyentes..$^{13}$

\section{ENTRE LA ILUSIÓN Y LA CRISIS}

Visto lo visto, es lógico que uno de los sacerdotes progresistas más destacados de la Cataluña de los sesenta, Joseph Bigordà, se haya referido a la gran «sotragada cultural del 68». Él vivió los cambios en la que entonces era su parroquia, Sant Medir, tanto a nivel cultural como social y religioso. De hecho, estas transformaciones pillaran desubicados a los católicos. Una vez que el Concilio Vaticano II dialoga con la sociedad, esta sociedad se transforma en algo muy diferente. Bigordà señala esta falta de adecuación: «el món nou que s'anunciava no tenia gran cosa a veure amb la societat que el Concili havia considerat com a interlocutora». ${ }^{14}$ Tal vez este hecho esté en relación con la utilización por el Vaticano II de categorías ya sobrepasadas por el debate intelectual de la época. El humanismo conciliar entraba en contradicción con el atihumanismo predicado, entre otros, por Althusser, tan influyente por entonces. Y, como ha señalado Denis Pelletier, pensadores como Lacan o Foucault cuestionarían los presupuestos antropológicos en los que se basaba el aggiornamento.

La ilusión e impulso renovador se mezclaban con la confusión y el malestar. Por eso, Joan Casañas, en su síntesis sobre el progresismo cristiano de Cataluña, señalaba 1968 como un año triste en la historia de los cristianos avanzados: «Hi havia vitalitat, però una crisi vinguda des de diferents vessants ho ofegaba gairebé tot, malgastava tots els esforços». ${ }^{15}$

Para los cristianos progresistas, el mayor problema, en palabras del periodista católico Lorenzo Gomis, no estribaba en vivir su fe en el mundo presente sino dar testimonio de esa fe dentro de una estructura eclesiástica anticuada. Esa era, precisamente, la raíz del conflicto entre los movimientos de Acción Católica especializada, como la JOC y la HOAC, y la jerarquía eclesiástica. A un lado,

\footnotetext{
${ }^{13}$ Véase el número 171 bis de El Ciervo (mayo de 1968), dedicado a Camilo Torres.

${ }^{14}$ Bigordà, J. 1997. Sant Medir des de la crònica i des del demà 1948-1998: 175-179 Barcelona: Biblària.

${ }^{15}$ Casañas, J. 1998. El progressisme catòlic a Catalunya (1940-1980): 315 Barcelona: La Llar del Llibre.
} 
los obispos, temerosos de unas organizaciones que se les iban de las manos y que, a su entender, se dedicaban demasiado a practicar el antifranquismo y demasiado poco a la espiritualidad. Al otro lado, los militantes cristianos, hartos de una Iglesia que ellos ven comprometida con los poderosos y a la que muchos abandonarán desengañados.

Se ha tendido analizar la crisis de la Acción Católica como un resultado de la pugna entre una jerarquía afecta al franquismo y unas bases contrarias a él. La existencia de una dictadura supone, un factor no negligible, pero no hay que perder de vista que este tipo de conflictividad interna se da también en países democráticos fruto del cuestionamiento de la autoridad eclesiástica que caracteriza al inmediato postconcilio. Sin embargo, las transformaciones sociales también inciden en un modelo de apostolado que empieza a demostrarse obsoleto. Pelletier, a partir del caso francés, apunta este desfase. La existencia de organizaciones concebidas en función de un ambiente social concreto (obrero, estudiantil, campesino), deja de tener sentido cuando el crecimiento económico unifica los estilos de vida. ${ }^{16}$

El auge de los partidos clandestinos acentuará, por otra parte, esta crisis interna. La existencia de canales de participación política lleva a muchos a cuestionarse la razón de ser de los movimientos cristianos. Éstos dejan de ser necesarios como vías desde donde expresar un descontento de tipo social.

La JOC, con todo, vive en 1968 su canto del cisne. En el estadio de Montjuic muestra su poder de convocatoria con un acto al que acudieron 4.000 personas que, de todas formas, supieron a poco ya que la previsión más pesimista era de 6.000. El encuentro venía a poner punto y final a la época gloriosa del jocismo. En plena efervescencia ideológica mundial, uno de los dirigentes del movimiento rindió «un cálido elogio a todos los luchadores del montón, que no tendrán una lápida como Che Guevara o Martin Luther King, pero que han muerto en los campos de concentración o en las minas de Bolivia luchando por la clase trabajadora». El mejor homenaje, sin embargo, no eran las palabras sino la continuación de la lucha. ${ }^{17}$ Así se resumía el espíritu combativo del momento.

El compromiso cristiano a favor de los trabajadores acabará llevando a muchos hacia el marxismo, visto como la única ideología que defendía «de verdad» los intereses obreros. «Fácilmente se tomaban las líneas marxistas con mucha seriedad», nos dice un antiguo consiliario de la JOC. ${ }^{18}$ Este movimiento editó, por cierto, los libros de Marta Harnecker. Sus textos serán el catecismo en

\footnotetext{
${ }^{16}$ Pelletier, D. 2002 : 77-103.

${ }^{17}$ Nota Informativa de la Jefatura Superior de Policía de Barcelona, 30 de junio de 1968. Archivo del Gobierno Civil de Barcelona, Correspondencia de Gobernadores, 177.

${ }^{18}$ Entrevista con el sacerdote Jaume Aregall, 7 de julio de 2003, realizada por el autor.
} 
el que se nutran numerosos militantes, ante la creciente aprehensión de la jerarquía. Cuando los jocistas quisieron sacar una segunda edición de esta pensadora, Joan Carrera, uno de los elementos más aperturistas entre las autoridades eclesiásticas, no dudó en reprenderles: «Oye, es que aquí siempre estáis con el tema del marxismo». ${ }^{19}$

Entre finales de los sesenta y principios de los setenta, el marxismo pasó a tener cada vez más protagonismo en ciertas comunidades cristianas, hasta impregnar de manera creciente los comentarios sobre el Evangelio.

A la hora de concretar políticamente la opción por esta ideología, al cristiano se le abría un amplio abanico de fuerzas de izquierdas. Primero, el partido por excelencia, el PSUC. Pero éste, en el radicalizado ambiente del momento, pasaba por demasiado moderado. «Partits com el PSUC aigualeixen la utopia», afirma un sacerdote que vivió aquella época. A su izquierda, toda una constelación de pequeños grupúsculos surgidos tras la estela del Mayo francés. Hay quien piensa que los cristianos se sintieron más cómodos en ellos porque, cansados del autoritarismo de la Iglesia, no deseaban formar parte de otra estructura vertical y burocrática, demasiado semejante a la que acaban de abandonar. ${ }^{20}$ Es una hipótesis plausible. Tampoco debemos olvidar quienes eran los grandes ídolos del momento: Camilo Torres, Che Guevara, Fidel Castro, Mao. En realidad, más que por un conocimiento profundo de su obra, se les admiraba como iconos de rebeldía. En el supermercado mundial de las ideas, la juventud antifranquista tomaba elementos que legitimaran su posición sociopolítica contestataria.

\section{CONFLICTO GENERACIONAL}

La nueva generación que se incorpora a la lucha democrática entrará pronto en conflicto con sus mayores. Pasqual Maragall, en sus memorias, nos habla de este enfrentamiento en el caso del FOC:

«El fet que les noves incorporacions al partit, bàsicament joves universitaris, arribessin més aviats seduïts per les tendències trotskistes i maoistes més radicals i engrescades pel moviment del Maig del 68, va provocar un enfrontament amb els que ells anomenaven una mica despectivament «socis fundadors»; nosaltres, els marxistes antidogmàtics, més sindicalistes i potser catòlics progressistes». ${ }^{21}$

\footnotetext{
${ }^{19}$ Entrevista con el antiguo jocista Manuel Navas, 29 de mayo de 2003, realizada por el autor.

${ }^{20}$ Miralles, J. 1983. Cristianos por el socialismo: 61 Barcelona: Fundació Jaume Bofill. Treballs d'arxiu Núm. 347.

${ }^{21}$ Maragall, P. 2008. Oda inacabada: 87 Barcelona: RBA.
} 
Daniel Cando, militante cristiano del FOC, se refirió con acritud a lo que él denominaba «estupidez moral» de la generación del 68. Este antiguo jocista estaba lejos de simpatizar con unos jóvenes que de ninguna manera le transmitían una imagen de seriedad y confianza. Todo lo contrario, ya que le parecen niños malcriados y arrogantes, muy distintos a los obreros que tienen que madrugar para ir al trabajo pero, en cambio, se quedan hasta muy tarde en reuniones clandestinas.

«Yo viví muy de cerca el auge de la estupidez moral de los estudiantes en el 68. Se dedicaron a fumar porros y a decirnos que estábamos anticuados porque nosotros no los fumábamos. Nos decían que teníamos prejuicios religiosos cuando les recriminábamos que, aunque se hartaban de follar con las niñas, eran más machistas que nadie».22

Tanta suspicacia es humanamente comprensible. El nuevo paradigma de militancia se aviene mal con la austeridad de revolucionario tradicional. Por eso, en la Barcelona de los últimos años del franquismo, se abre paso una nueva forma de contestación, en la línea del mayo francés, que cuestiona por unidimensional el estilo clásico de hacer política, al que se reprocha escasa sensibilidad en aspectos de la vida tan importantes como el placer, la imaginación y la sexualidad. Esta cosmovisión hedonista será, en la práctica, la mayor aportación de la revuelta parisina, menos efectiva en el terreno político que en el cultural.

En cualquier caso, lo cierto es que el ideal del militante sacrificado, para bien o para mal, pasa de moda.

Dentro de estas coordenadas se explica mejor el rechazo de amplio alcance suscitado, dentro de las filas católicas, por la encíclica Humanae Vitae, en la que Pablo VI se posiciona contra los métodos anticonceptivos. En un contexto dominado por la inestabilidad interna, la desobediencia a las directrices vaticanas tiene una profunda repercusión. Muchos, cuando rompen con los tabúes sexuales asumidos en el pasado, rompen también el último cordón umbilical que les une a la fe. ${ }^{23}$ Poco antes de su muerte, Roser Bofill, la periodista de $E l$ Ciervo, recordó los numerosos casos de gente que dejaba la fe precisamente por el escándalo de la encíclica: «Molta gent va deixar el cristianisme per aixó, molts. Perquè s'ho prenien en serio», afirmó con tono dolorido. ${ }^{24}$

No obstante, otros reivindicarán desde posiciones cristianas una mayor amplitud de miras en este terreno. Lorenzo Gomis, sin ir más lejos, reclamó el

\footnotetext{
${ }^{22}$ García Alcalá, J. A. 2001. Historia del Felipe (FLP, FOC y ESBA): 241-42 Madrid: Centro de Estudios Políticos y Constitucionales.

${ }^{23}$ Miralles, J. 1983: 88.

${ }^{24}$ Declaraciones para L’Església rebel. Tomamos la cita de la transcripción completa de la entrevista que sirvió de base para el documental.
} 
derecho del cristiano a decidir en conciencia: «Entre estos problemas está sin duda el de la intimidad conyugal y la regulación de la natalidad, que muchos no sabríamos considerar resuelto con una simple combinación de encíclica pontificia y silencio obsequioso»..$^{25}$

El Ciervo, vale la pena puntualizarlo, fue una de las primeras revistas en publicar un artículo contra la encíclica.

\section{AdmiRANDO EL RIESGO}

Entre los cristianos de izquierda destaca, sin duda, la figura de Alfonso Carlos Comín, célebre por su intento de compatibilizar la fe cristiana con la teoría marxista. En esta época lo encontramos como militante de Bandera Roja, uno de los partidos de extrema izquierda nacidos del humus sesentayochista. No está de más, por tanto, que nos detengamos a considerar su análisis, en el que expresa su entusiasmo ante unos hechos tan insólitos. En un momento en el que parecía imposible que se hiciera la revolución en un país occidental, estudiantes y obreros venían a recordar lo contrario: «Como la primavera de la Comuna de París, ésta de 1968 ha reanimado las esperanzas de los que, fatigadamente, veían transcurrir la historia sin otra salida que la embrutecedora «ilusión» de la sociedad del consumo». Los estudiantes, con su rebeldía, ponían en cuestión los fundamentos de la sociedad capitalista. Demostraban que su función, como universitarios, era trabajar por el cambio social, no servir a los intereses de la burguesía buscando en la carrera únicamente un medio de autopromoción personal. Colocaban así los cimientos de una auténtica revolución cultural, en abierta oposición a la sociedad de clases. Los trabajadores, mientras tanto, reivindicaban «que las fábricas pueden y deben funcionar con su intervención directiva». ${ }^{26}$

La simpatía de Comín por los estudiantes franceses se debe más a una coincidencia ética que política. Les admira porque han actuado. Se han arriesgado. Optan por la audacia, no por la prudencia conformista. Quizá no tengan un programa político estructurado, ni sepan demasiado bien lo que quieren, pero se han puesto en marcha para lograr un cambio, exponiéndose a la represión de un estado que no duda en recurrir a la fuerza si ve tambalearse el sistema capitalista. Sus actos suponían un cambio cultural que apuntaba hacia el surgimiento de un hombre nuevo, solidario, comprometido con la causa de la revolución. El

${ }^{25}$ Gomis, L. 1968. «Un problema moral». El Ciervo 175-176.

${ }^{26}$ Comín, A. «La resurrección de la cultura», en Obras Completas. vol. VI, 45-46. Su biografía en Martínez Hoyos, F. 2009. La cruz y el martillo. Alfonso Carlos Comín y los cristianos comunistas: Barcelona, Rubeo. 
intelectual, si quiere ser útil, ha de situarse en esta línea. No debe permanecer en su torre de marfil, dedicado a conocimientos inservibles, sino zambullirse en la vida real.

\section{UNA COMPARACIÓN SUTIL}

Tomemos ahora otro símbolo de la Iglesia aperturista, El Ciervo, que no tardó en informar de lo que veía como un fenómeno nuevo: la revolución en una sociedad consumista. Vistas desde Cataluña, las movilizaciones obreras no dejaban de parecer extrañas a algunos ¿Cómo era posible que unos trabajadores con cuatro semanas de vacaciones se lanzaran a la calle?

Las páginas de la revista intentaron clarificar unos acontecimientos que se percibían confusos, con una protesta estudiantil que parecía radical, aunque inconcreta, y una protesta obrera más precisa aunque también más moderada. ¿Por qué, en resumidas cuentas, semejante estallido? El detonante había que buscarlo en la exclusión social que los jóvenes, al igual que los pobres, sufrían en todo el mundo. Ese era uno de los males encubierto tras lo que parecía, a primera vista, una revuelta gratuita, en un «mundo feliz» gobernado por la publicidad. Los estudiantes franceses, llegado el momento de incorporarse al mundo de sus mayores, se veían privados de responsabilidad e iniciativa. No se resignaban, sin embargo, a vivir domesticados. Su protesta había conseguido que dos importantes políticos, De Gaulle y Pompidou, les prometieran participación y reforma. Se habían hecho oír, sí, pero sólo tras una rebelión desordenada y anárquica, señal incuestionable de que el sistema carecía de canales adecuados para expresar manifestaciones de descontento.

Lorenzo Gomis, al comentar Mayo del 68, sin duda tiene la mente puesta en la realidad española. Por eso deja ir algunos comentarios, en principio referidos al país vecino, que cualquier lector medianamente inteligente aplicaría al franquismo. «Se ha creído que una sociedad podía vivir en paz gracias al poder de pocos y la resignación de muchos». La transformación de la realidad, por el contrario, es tarea de todos. La indirecta no podía ser más clara: había que acabar con un régimen tan antidemocrático como el español. La Iglesia, por su parte, debía aplicarse en favorecer la convivencia, misión crucial en la que todavía no había acertado.

El director de El Ciervo tampoco se priva de denunciar el carácter represivo de las fuerzas del orden. El empleo de la brutalidad contra los jóvenes, lejos de eliminar el problema, sólo ha conseguido darle una dimensión que antes no tenía. Para apoyar su tesis, Gomis se basa en la carta al International Herald Tribune de un americano testigo de los hechos, donde podía leerse: «El uso de las fuerzas represivas de «la ley y el orden» contra la masa de la gente representa 
a menudo el mayor ultraje a la ley y el orden y es la causa fundamental de la violencia destructiva que se sigue». En el mismo sentido aparece citado un editorial de The Times, no sin advertir que sus fuentes no cojean precisamente del lado revolucionario. El periódico londinense también acusaba a los cuerpos policiales de crear disturbios más que de prevenirlos, al ser incapaces de utilizar procedimientos distintos a la violencia extrema.

La rebelión estudiantil, tanto la francesa como la de otros países (Polonia, por ejemplo), tenía, a juicio de Gomis, una raíz: la inadecuación de la Enseñanza Superior a las necesidades de la sociedad. Y, al mismo tiempo, expresaba la insatisfacción de los jóvenes respecto a las clases dirigentes, acostumbradas a perpetuarse en el poder. ${ }^{27}$ Justo lo mismo que sucedía en España.

Hay que tener en cuenta, asimismo, el resto de artículos que El Ciervo dedicó a la rebelión. En una primera crónica, escrita desde la capital francesa, Julián Gallego informaba de las agitaciones y criticaba a De Gaulle por agitar el espantajo del comunismo, algo que sin duda el lector español interpretaría, también, en clave local. Por su parte, Enrique Ferrán trató de explicar qué deseaban los trabajadores galos, en un artículo ilustrado con la imagen de una recogida de fondos a favor de unos huelguistas. En la que, detalle significativo, uno de los participantes es un sacerdote, como delata su alzacuello. A su alrededor se observaban pancartas de las diferentes organizaciones obreras.

Ferrán apuntaba la escasez del salario como factor de descontento, pero precisaba que no lo explicaba todo. Las reivindicaciones no sólo apuntaban a objetivos materiales, también a obtener mayor participación y responsabilidad en la organización de la empresa. ${ }^{28}$

Por su parte, Juan Gomis formulaba una reflexión importante: la rebelión desde abajo había obligado al poder, siempre reticente al cambio, a efectuar reformas que de otro modo nunca habrían admitido. Una vez más, el comentario resulta de inequívoca aplicación en la España de Franco, con un gobierno reacio a toda evolución en sentido aperturista. Francia, sin embargo, demostraba que las cosas no tenían porque seguir siendo de la misma manera, incluido un ámbito, la organización de la economía, hasta ese momento de apariencia inamovible. Al ocupar grandes empresas, los obreros galos colocaban sobre la agenda la necesidad de una sociedad con mayores cotas de participación. De esta forma, quedaba una puerta abierta hacia una democracia más real. ${ }^{29}$

\footnotetext{
${ }^{27}$ Gomis, L. 1968. «La conspiración de las chisteras». El Ciervo 171. Del mismo autor, «La convivencia humana». El Ciervo 172.

${ }^{28}$ Gallego, J. «Las barricadas de Mayo». Ferrán, E. «¿Qué quieren los obreros?». Ambos artículos en El Ciervo 172.

${ }^{29}$ Gomis, J. «Diario 1968». El Ciervo 172.
} 
Pasada ya la efervescencia, Antonio Marzal, señalaba desde París que, pese a las apariencias de vuelta a la normalidad, nada era exactamente como antes. En su opinión, la gran victoria electoral del general De Gaulle no suponía un desmentido a los acontecimientos de mayo, ya que ambos hechos no tendrían nada que ver y, además, el parlamento no constituía una institución decisiva en la vida nacional. La cuestión era dilucidar si la revolución se había agotado o, por el contrario, sólo se vivía una breve tregua a la espera de nuevas batallas. La segunda opción constituía, a su juicio, la respuesta correcta. Porque la pérdida del miedo o la «politización clara de inmensos sectores estudiantes», anunciaban una transformación en marcha. ${ }^{30}$

\section{EL 68 DEL CLERO}

Hasta aquí nos hemos centrado en los seglares, pero... ¿qué decir de los sentimientos del clero más progresista? Podemos intuirlos a través del boletín interno Correspondència. En sus páginas encontramos un artículo del sacerdote Antoni Totosaus, del obispado de Barcelona, en el que se califica de profundamente espiritual a la revolución parisina. Ésta se había iniciado a partir de pequeñas acciones reivindicativas como exigir una biblioteca actualizada, libertad de reunión o una nueva metodología educativa. Por desgracia, la Universidad, incapaz de responder a este movimiento renovador, recurría a las sanciones. La ocupación de la Sorbona, con todo lo que tenía de gesto de afirmación democrática, constituía, según Totosaus, una «gran efusió de l'esperit». Los estudiantes protagonizaban una toma de conciencia colectiva de su explotación, frente al autoritarismo de los profesores, frente a una sociedad hipócrita que sólo concebía a los universitarios como instrumento del sistema capitalista. Su movimiento suponía el rechazo de un mundo burocratizado, en el que palabras como libertad y democracia se habían vaciado de contenido.

No hay, sin embargo, que exagerar. Para Jaume P. Sayrach, entonces cura en Santa Coloma, no existe conexión entre lo sucedido en Francia y un movimiento cristiano impulsado por el Vaticano II pero que, de hecho, es anterior. En Barcelona, el clero más avanzado se lanzó a la lucha antifranquista impulsado por su fe religiosa, escandalizado por el apoyo de la Iglesia, en tanto institución, a un régimen dictatorial. Así, en muchos barrios, detrás de las reivindicaciones vecinales, se halla un sacerdote. Su experiencia cotidiana es la de la precariedad que se vive en los suburbios, con calles sin asfaltar, falta de escuelas, etc. No son comunistas, al contrario de lo que suponen las autoridades; no quieren hacer subversión, pero sus actos, ante la ausencia de libertades, lo son

\footnotetext{
${ }^{30}$ Marzal, A. 1968. «Octubre después de mayo». El Ciervo 175-176.
} 
inevitablemente. Por ejemplo, las reuniones de hombres y mujeres para tratar temas cívicos adquieren un claro significado político. ${ }^{31}$

Pero el sector del clero socialmente más comprometido acabará optando por la secularización. Durante unos años, la sangría será continua, aunque lo cierto es que el fenómeno no se circunscribe sólo a la España franquista. En todo el mundo se produce un aumento imparable de los abandonos, que de 167 entre 1962 y 1963 pasan, siete años más tarde, a más de 3.600, según cálculos estimativos. La mayoría, hombres de entre treinta y cuarenta años. En la diócesis de Barcelona fueron alrededor de doscientos, en medio de un descenso acusado del número de ordenaciones y de vocaciones.

Como dijo el sociólogo Joan Estruch, en esos años se produce el colapso de las «estructuras de plausibilidad» de la institución eclesiástica. En poco tiempo, el sacerdocio pasa de ser, prácticamente, casi el único camino posible de perfección cristiana, además de un medio evidente de promoción social, a sufrir una desvalorización profunda de su estatus. Se quiera o no, al cura ya no se le identifica con el personaje sagrado de antaño. Se abre así un inmenso vacío: el sacerdote tradicional, dispensador de sacramentos e influyente dentro de la comunidad, no cuenta con nada que le sustituya. Los modelos alternativos de ministerio, sean los curas obreros o los sacerdotes casados, no pasan de ejercer una influencia marginal. La mayoría de la gente, más allá de las minorías creativas de las que habla Ratzinger, incluso desconoce su existencia.

Las razones de los que cuelgan la sotana son diversas. Unos, llevados por un ímpetu mesiánico, se habían creído los auténticos portadores del Evangelio frente a un estamento clerical apoltronado en sus privilegios. A la hora de la verdad, comprobarán que sus feligreses no están dispuestos a secundar su radicalidad, por ejemplo en su crítica al ministerio como una simple administración de sacramentos, o bien en un camino que incluye muchas veces la opción política a favor de la izquierda y la extrema izquierda. Los laicos más conservadores, desconcertados por las reformas, abandonan entonces las parroquias.

No les resulta fácil, en efecto, comprender ciertas opciones rompedoras. ¿Cómo es posible que unas personas que han estado años preparándose, en el seminario, renuncien a la paga del Estado para convertirse en simples trabajadores? Este fue el caso de Eduard Fornés, un vicario de Sabadell que se hizo cura obrero y empezó a trabajar de soldador. Una apuesta, según su testimonio, no siempre aceptaba entre la gente del pueblo, que seguía considerando al sacerdote

${ }^{31}$ Totosaus, A. 1968. «Un nou profetisme en el món: Moviment 22 de Març». Correspondència. Full de diàleg sacerdotal 60. Entrevista personal a Jaume P. Sayrach, 8 de enero de 2009. 
un ser «solucionalotodo». Una especie de brujo, en palabras de Fornés. Justo lo que él, igual que otros compañeros, no estaba dispuesto a ser. ${ }^{32}$

Por su parte, Jaume Patrici Sayrach nos cuenta el desfase entre unos sacerdotes que cuestionaban la sacramentalización, a sus ojos rutinaria, y unos fieles que no entendían el sacerdocio si no era desde los bautizos, las comuniones y las bodas. Así, cuando Sayrach preguntaba a unos novios si deseaban casarse, o porque no se casaban por lo civil, se producían reacciones de desconcierto. En otras ocasiones, la gente tampoco entendía su rechazo a ocuparse de un muerto a altas horas de la madrugada. ¿Por qué le traían un cadáver, como si él fuera la funeraria? Con unos paradigmas tan opuestos sobre lo que debía ser un representante eclesial, no es extraño que se dieran situaciones enojosas ni comentarios del tipo «Este no es ni un cura ni es nada». ${ }^{33}$

Mientras tanto, los curas avanzados ven como se cuestiona su posición desde presupuestos de la extrema izquierda. Se les acusa de incoherencia por mantenerse, pese a todo, dentro de las filas católicas. «¿Qué haces en la Iglesia?, si es enemiga nuestra», escuchan más de una vez. Cierto que en esos momentos, desde el Partido Comunista, se expresaba admiración hacia los sacerdotes obreros, pero nos referimos al sector del clero políticamente más radical. El que consideraba que el PCE no era revolucionario sino reformista, uno de los peores insultos en la jerga del momento. Para afrontar estas situaciones difíciles, tales sacerdotes hubieran necesitado el apoyo de la comunidad eclesial en su conjunto pero, por desgracia, no fue así. Los obispos no les entendían, los sacerdotes más tradicionales les miraban mal. Todo ello les supone una decepción fortísima, según indica Francesc Núñez en su estudio sobre «les plegades».

En otros casos, el factor a considerar, aunque calibrar su importancia resulte complicado, es el descubrimiento de la mujer, sobre todo teniendo en cuenta la insuficiencia de la formación emocional dispensada en el seminario. En el trato con el otro sexo aparecerán sentimientos nuevos que los protagonistas, inmaduros en este campo, no siempre sabrán gestionar. No obstante, por los testimonios disponibles, la hipótesis más probable indica que no fue éste el motivo fundamental. Siempre han existido en la Iglesia sacerdotes «amancebados» clandestinamente, pero ahora nos referimos a un clero vocacional, hasta ese momento especialmente activo y concienciado de su misión. El mejor formado de la historia de Cataluña y de España. ¿Qué sucede para que la Iglesia pierda este capital humano tan valioso, imposible de sustituir?

\footnotetext{
${ }^{32}$ El testimonio de Fornés en un reciente libro sobre la cárcel concordataria de Zamora: Zelaieta, A; Jimenez, E. 2011. Zamorako apaiz-kartzela. Eliza eta Estatuaren presondegia (1968-1976): 238-239 Tafalla, Txalaparta.

${ }^{33}$ Transcripción de la entrevista a Sayrach realizada para el documental L'Església rebel.
} 
Todo parece indicar que los protagonistas primero rompen con una institución incapaz de responder a sus expectativas. Detrás de sus abandonos, suele haber una historia de frustración con sus superiores jerárquicos, aferrados a conceptos obsoletos de otras épocas. Resultan expresivas las recientes declaraciones de Jordi Bertrán, en el documental L'Església rebel, acerca de la reacción de un grupo de curas cuando el arzobispo de Barcelona, Modrego, pretendió convencerles de que en el Concilio no había pasado nada. Le abuchearon.

Consumada la ruptura, y sólo entonces, vendrían los emparejamientos, consecuencia de las secularizaciones y no causa de las mismas.

En todo caso, la hemorragia entre los efectivos del clero fue considerable, y tardó mucho tiempo en sanar. Aunque convendría distinguir, como hace Jaume P. Sayrach, entre quienes colgaron los hábitos y los muchos que fueron expulsados. ${ }^{34}$ Se produjeron entonces situaciones de fortísimo sufrimiento humano, a veces en forma de depresiones. Muchos no saben como contárselo a la familia, mientras antiguos compañeros les señalan como desertores. De la noche a la mañana, los que eran sacerdotes ejemplares pasan a convertirse en proscritos.

\section{EL PRINCIPIO DEL FIN}

Después de todo este recorrido, podemos concluir, siguiendo a Casañas, que 1968 marcó el principio del fin de todos los progresismos, incluido el cristiano. Se puede objetar que después de esta fecha aún encontramos hitos importantes, como la Asamblea Conjunta, donde la Iglesia pide perdón por su papel en la guerra civil. Y, poco más tarde, la influencia de la teología de la liberación se hará notar en el surgimiento de Cristianos por el Socialismo. Con todo, la tendencia general es de crisis, marcada por dos fenómenos de consecuencias devastadoras: el hundimiento de la Acción Católica especializada, reducida a la mínima expresión, y la secularización del buena parte del clero, con la marcha de parte de sus elementos más progresistas y comprometidos.

En Cataluña, sin embargo, este fracaso habría tardado más en notarse por las urgencias que imponía la lucha contra la dictadura. La prioridad no estaba en lo que sucedía en el extranjero sino en el estado de excepción que el régimen iba a declarar el año siguiente.

¿Fueron los cristianos de izquierdas unos ingenuos que, en su entusiasmo, creyeron que arrastrarían a su lado al conjunto de la Iglesia? Esta es la opinión

${ }^{34}$ Núñez i Mosteo, F. 2006. Les plegades. Sacerdots secularitzats: Barcelona: Mediterrània. Entrevista personal a Jaume P. Sayrach, op. cit. 
de un ex sacerdote, Jaume Barallat, que colgó los hábitos, según cuenta en sus memorias, por no aceptar una situación de monolitismo en la que no le quedaba otra que aceptar una autoridad infalible. ${ }^{35}$ En realidad, para entonces, tal monolitismo ya no existía. Puede que los católicos más avanzados pecaran de inocentes, puede que padecieran de izquierdismo en el sentido leninista, el de enfermedad infantil, pero su esfuerzo no fue en vano. Hicieron avanzar a la Iglesia hacia posiciones más aperturistas con la aceptación de valores como la democracia y el pluralismo. Aunque si ellos hicieron a la Iglesia, también es cierto que la Iglesia les hizo a ellos funcionando como agente socializador. Les inculcó unos determinados valores religiosos, políticos, sociales y culturales que, de una manera u otra, incidieron en sus trayectorias futuras. Dar testimonio del Evangelio equivalía a comprometerse seriamente con las realidades llamadas «temporales», de cara a una acción por la justicia. Los movimientos cristianos se convertían, así, en una escuela de ciudadanos responsables a los que ayudaban a madurar como personas. Junto a este bagaje humano, proporcionaban a sus miembros habilidades «técnicas» como saber hablar en público o dirigir una reunión. ${ }^{36}$

En la estela del Vaticano II, pero también de la revolución cubana, el mayo francés o la teología de la liberación, los nuevos movimientos eclesiales, como Cristianos por el Socialismo, no quieren limitarse a mantener la ortodoxia. Lo importante, para ellos, será la ortopraxis. Una actuación correcta, del lado correcto, es decir, el de los oprimidos. La idea de denuncia profética, tan cara a esta corriente eclesial, se reformula para dar un paso más y plantear lo que debe ser una «lucha profética». La cuestión es preguntarse si la misión de la Iglesia no consiste en luchar «codo con codo con los demás oprimidos, y críticamente a través de los medios que éstos se den, luchar para trastocar el orden que posibilita su existencia como tales». ${ }^{37}$

Es evidente que no todos, dentro de la Iglesia, compartirán estos puntos de vista. Para el obispo auxiliar Carrera se había producido un movimiento de péndulo: los cristianos pasaban de la suspicacia ante el mundo a postrarse ante él, de manera acrítica, sacralizando conceptos como pueblo o clase obrera. El creyente, según este análisis, si antes pecaba de excesiva seguridad en su fe, hasta

\footnotetext{
${ }^{35}$ Barallat, J. 2001. Adéu, gàbia dels miralls! Ventures i desventures d'un excapellà : Barcelona: Mediterrània.

${ }^{36}$ La Iglesia como agente socializador de la militancia política en Costa i Riera, J. 1997. Dels moviments d'Església a la militància política: Barcelona: Mediterrània.

${ }^{37}$ La lucha profética de los Cristianos en la España del 73. Un ensayo de interpretación comunitaria. Barcelona. Cristianos por el Socialismo, febrero de 1974.
} 
el punto de querer imponerla, ahora se mostrará demasiado acomplejado, sin atreverse a un anuncio explícito del Evangelio. ${ }^{38}$

La reflexión historiográfica ha de ser prudente y no dar por buenos, sin reflexión, los discursos de los actores implicados. Tampoco el del cristianismo avanzando, porque la tentación de construir una historia maniquea, con sus héroes y sus malvados, es a veces muy fuerte. Nada tiene de nuevo decir que los obispos franquistas pecaban de dogmáticos, pero... ¿acaso ciertos católicos revolucionarios no poseen la misma convicción de ser los únicos detentadores de la verdad? ¿No cayeron nunca en un puritanismo intolerante? Jordi Figuerola e Isabel Juncosa, en su estudio sobre la diócesis de Barcelona, nos dicen que algunos pretendieron correr demasiado en muy poco tiempo, de manera que abogaron por una pastoral desenraizada de la mentalidad de la mayoría de sus fieles. ${ }^{39}$ En ocasiones, con formulaciones bastante heterodoxas imposibles de asumir por la mayoría. Veamos, sin ir más lejos, determinadas prácticas len la JOC de Sabadell, a finales de los sesenta y principios de los setenta. Algunos militantes, desde una fe vivida en comunión con el compromiso obrero, tomaban un trozo de pan, un poco de vino y comulgaban, pese a que la celebración de la eucaristía implica necesariamente un sacerdote. «Con los curas o sin los curas, el valor para nosotros era el mismo», afirma Manuel Navas, antiguo jocista. ${ }^{40}$ Con la perspectiva del tiempo, Jaume Aregall, exconsiliario del movimiento, recuerda el hecho como una especie de chiquillada que demuestra únicamente la inquietud de unos jóvenes por vivir sus convicciones religiosas, carentes de sacerdotes que les pudieran acompañar. ${ }^{41}$ Travesura o no, la anécdota refleja el espíritu antijerárquico de ciertos sectores católicos.

No cabe duda de que los cristianos más avanzados perseguían purificar su fe de una manera sincera y generosa, pero no supieron medir los tiempos. Su intento de transformar en poco tiempo una institución de casi dos mil años tenía que acabar, por fuerza, en fracaso.

Pensemos, asimismo, en lo que le sucedió al sacerdote y alcalde de Santa Coloma, Lluís Hernández. En una comunidad cristiana le criticaron por aceptar un cargo político, como si fuera un traidor a la causa, porque una cosa es ser instancia crítica del poder y otra aceptar algo que mancha, corrompe. Él respondió que deseaba cambiar cosas. Seguiría con sus actividades de siempre, sólo que con más medios. ${ }^{42} \mathrm{Y}$ ejemplos de esta mentalidad un tanto inquisitorial, en otros

\footnotetext{
${ }^{38}$ Carrera, J. 1994: 28-29.

${ }^{39}$ Figuerola, J; Juncosa, I. 2008: 150.

${ }^{40}$ Entrevista a Manuel Navas, op. cit.

${ }^{41}$ Entrevista con Jaume Aregall, op . cit.

${ }^{42}$ Entrevista al jesuita Joan Travé realizada por el autor, 3 de abril de 2008.
} 
ámbitos, podrían multiplicarse. Tener un coche o llevar a tus hijos a una escuela privada equivalía a ser un burgués, desde este asfixiante moralismo.

Transacción contra pureza doctrinaria, el mismo antagonismo que refleja el caso de Hernández sugiere la heterogeneidad del concepto de católicos progresistas. Unos más a la izquierda, otros menos; unos más radicales en su contestación a la Iglesia, otros no tanto. Pero, de una forma o de otra, todos encabezaron el «desenganche» de la Iglesia respecto al franquismo. Protagonizaron así una transición religiosa que contribuiría, poco más tarde, a hacer viable la transición política. ${ }^{43}$

\section{BiBLIOGRAFÍA} Trotta.

Blázquez, F. 1991. La traición de los clérigos en la España de Franco: Madrid,

Barallat, J. 2001. Adéu, gàbia dels miralls! Ventures i desventures d'un excapellà : Barcelona: Mediterrània.

Barrau, G. 1998. Le mai 68 des catholiques : París : Éditions de l'Atelier.

Bigordà, J. 1997. Sant Medir des de la crònica i des del demà 1948-1998: 175-179 Barcelona: Biblària.

Carmona Fernández, Francisco J (Coord.). 2010. Historia del Cristianismo IV. El mundo contemporáneo: Madrid: Trotta.

Carrera, J. 1994. Del postconcili al postprogressisme: Barcelona: Mediterrània.

Casañas, J. 1998. El progressisme catòlic a Catalunya (1940-1980): Barcelona: La Llar del Llibre.

Compagnon, O. 2008. "Le 68 des catholiques latinoaméricains dans une perspective transatlantique". Materiales de seminarios, dentro de nuevomundo.revues.org/47243

Costa i Riera, J. 1997. Dels moviments d'Església a la militància política: Barcelona: Mediterrània.

\footnotetext{
${ }^{43}$ Sobre el tema «transición política, transición religiosa», véase Díaz Salazar, R. 1981. Iglesia, dictadura y democracia: Madrid: HOAC. Blázquez, F. 1991. La traición de los clérigos en la España de Franco: Madrid, Trotta. Piñol, J. M ${ }^{\text {a }}$. 1999. La Transición democrática de la Iglesia española: Madrid: Trotta. Cueva Merino, J. de la; López Villaverde, A. L. (Coords.). 2005. Clericalismo y asociacionismo católico en España: de la restauración a la transición: 255-278. Cuenca: Universidad de Castilla-La Mancha. Montero, F. 2009. La Iglesia: de la colaboración a la disidencia (1956-1975): Madrid: Encuentro.
} 
Cueva Merino, J. de la; López Villaverde, A. L. (Coords.). 2005. Clericalismo y asociacionismo católico en España: de la restauración a la transición: Cuenca: Universidad de Castilla-La Mancha.

Díaz Salazar, R. 1981. Iglesia, dictadura y democracia: Madrid: HOAC.

Figuerola, J; Juncosa, I. 2008. L'Església catalana durant el franquisme (19391975), vol III: Barcelona: Claret.

García Alcalá, J. A. 2001. Historia del Felipe (FLP, FOC y ESBA): Madrid: Centro de Estudios Políticos y Constitucionales.

Graziano, M. 2012. El siglo católico: Barcelona, RBA.

Maragall, P. 2008. Oda inacabada: 87 Barcelona: RBA.

Martínez Hoyos, F. 2007. «Cristianos contra Franco en Cataluña (1939-1975)». Historia del Presente 10: 61-80.

Martínez Hoyos, F. 2009. La cruz y el martillo. Alfonso Carlos Comín y los cristianos comunistas: Barcelona, Rubeo.

Miralles, J. 1983. Cristianos por el socialismo: Barcelona: Fundació Jaume Bofill. Treballs d'arxiu Núm. 347.

Montero, F. 2009. La Iglesia: de la colaboración a la disidencia (1956-1975): Madrid: Encuentro.

Núñez i Mosteo, F. 2006. Les plegades. Sacerdots secularitzats: Barcelona: Mediterrània.

Pelletier, D. 2002. La crise catholique : París: Payot.

Piñol, J. Mª 1999. La Transición democrática de la Iglesia española: Madrid: Trotta.

Polo, X. 2005 «Todos los catalanes son una mierda»: Bacelona: Proa.

Rovira Belloso, J. M. 2008. Dios: Padre, Hijo y Espíritu Santo: Salamanca: Secretariado Trinitario.

Zelaieta, A; Jimenez, E. 2011. Zamorako apaiz-kartzela. Eliza eta Estatuaren presondegia (1968-1976): Tafalla, Txalaparta. 